\title{
Expanding access to family planning for married adolescent girls in the urban slums of Dhaka
}

Fauzia Akhter Huda

Nancy Termini LaChance

Follow this and additional works at: https://knowledgecommons.popcouncil.org/departments_sbsr-rh

Part of the Demography, Population, and Ecology Commons, Family, Life Course, and Society Commons, International Public Health Commons, Maternal and Child Health Commons, and the Women's Health Commons How does access to this work benefit you? Let us know!

\section{Recommended Citation}

Akhter Huda, Fauzia and Nancy Termini LaChance. 2018. "Expanding access to family planning for married adolescent girls in the urban slums of Dhaka," STEP UP Policy Brief. Dhaka: icddr,b. 


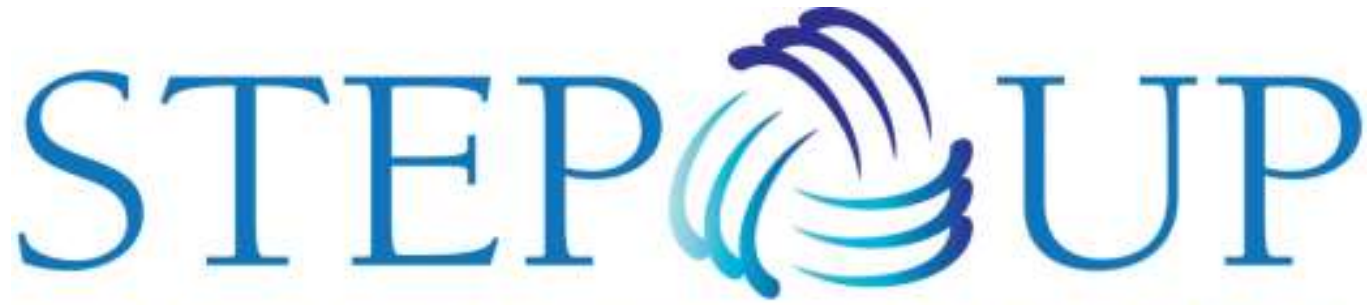

STEP UP generates policy-relevant research to promote an evidencebased approach for improving access to family planning and safe abortion.

We work in Bangladesh, northern India, Ghana, Kenya, and Senegal.

Population Council Coordinating Partner

African Population and Health Research Center icddr,b

London School of Hygiene and Tropical Medicine

Marie Stopes

International

Funded by

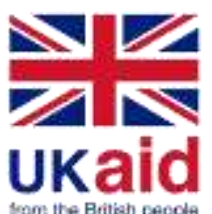

\section{Expanding Access to Family Planning for Married Adolescent Girls in the Urban Slums of Dhaka}

\section{SUMMARY}

Early pregnancy is associated with adverse health, social, and economic consequences for girls, and Bangladesh has an adolescent fertility rate that is among the highest in the region. Poor, slum-dwelling girls are especially vulnerable. This Policy Brief outlines a project that icddr,b, a STEP UP project partner, initiated to test three innovative strategies aiming to support the unmet family planning needs of these girls. This Brief concludes with government-level policy and programme recommendations based on the evidence of this project for leveraging existing government health programmes to better serve the needs of married adolescent girls and reduce their risks of early pregnancy.

\section{INTRODUCTION}

In Bangladesh, the adolescent fertility rate of 128 births/1000 for girls aged $15-19$ years is among the highest in the Asia pacific [1]. On average, adolescent girls marry 3-4 years below the legal age of 18 .

Married adolescent girls are under significant social and family pressure to demonstrate their fertility by becoming pregnant quickly after marriage [2]. In addition to early marriage, early childbearing is exacerbated by girls' lack of access to family planning (FP) and reproductive health $(\mathrm{RH})$ services.

Evidence shows that $20 \%$ of births to teenage mothers were unintended [2] and unintended pregnancies are over twice as high among married adolescent girls in the slums compared to those girls in non-slum areas of Bangladesh [3].

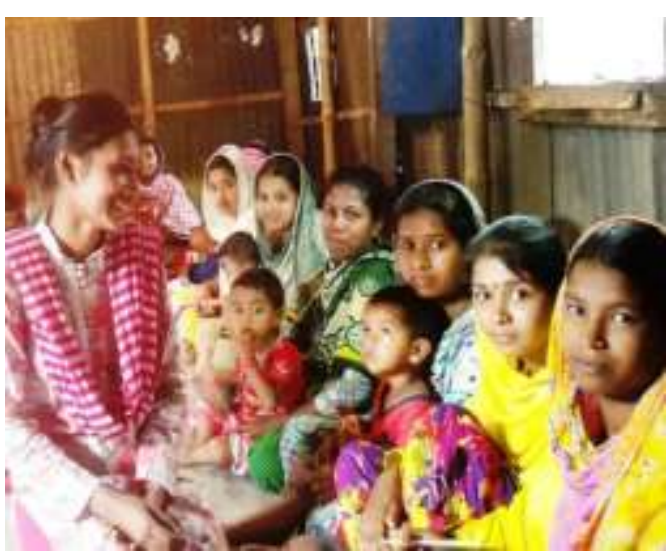

Because early pregnancy is associated with adverse health, social, and economic consequences - including complications of pregnancy, preterm birth and underweight babies, spousal violence, lower educational attainment, and limited ability to earn income - low-income girls are especially vulnerable to the problems posed by early pregnancy [4]. (Figure 1) 


\section{THE PROJECT}

icddr,b, through the Strengthening Evidence for Programming on Unintended Pregnancy (STEP UP) project, tested innovative strategies to address the vulnerability of married adolescent girls in the slums. These interventions addressed unintended pregnancy and unmet need for family planning among married adolescent girls in two slums in Dhaka city - Kamrangirchar and Mirpur. Another two slums, Rayerbazar and Shekhertek, were selected as control areas. The project provided valuable lessons on the potential to use three existing community initiatives: married adolescent girls clubs, brac Shasthya Shebikas' (community health volunteer) program, and engaging Marriage Registrars to expand access to FP information and services to girls.

\section{INTERVENTIONS}

\section{Married Adolescent Girls Club (MAG Club)}

The international NGO, brac, has significant experience running clubs for married and/or unmarried adolescent boys and/or girls in Bangladesh. icddr,b collaborated with brac to replicate their club model to target married adolescent girls in the urban slums. Club leaders were recruited and trained by icddr,b on matters relevant to adolescent sexual and reproductive health (SRH), unintended pregnancy, $\mathrm{FP}$, and early marriage.

Throughout the project period, 1,709 girls aged 15-19 years participated in these clubs. MAG club meetings took place in 10 brac primary schools within the two slums, Kamrangirchar and Mirpur. An average of 20 married adolescent girls participated in each session, each of whom could attend up to 12 club sessions (one per month) during the one-year intervention period (March 2015-Feb. 2016).

\section{Fig. 2: Family planning picture book}

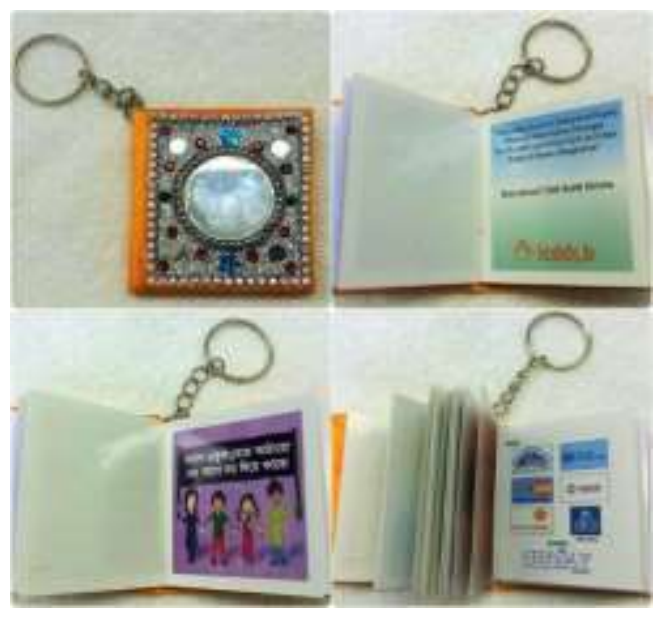

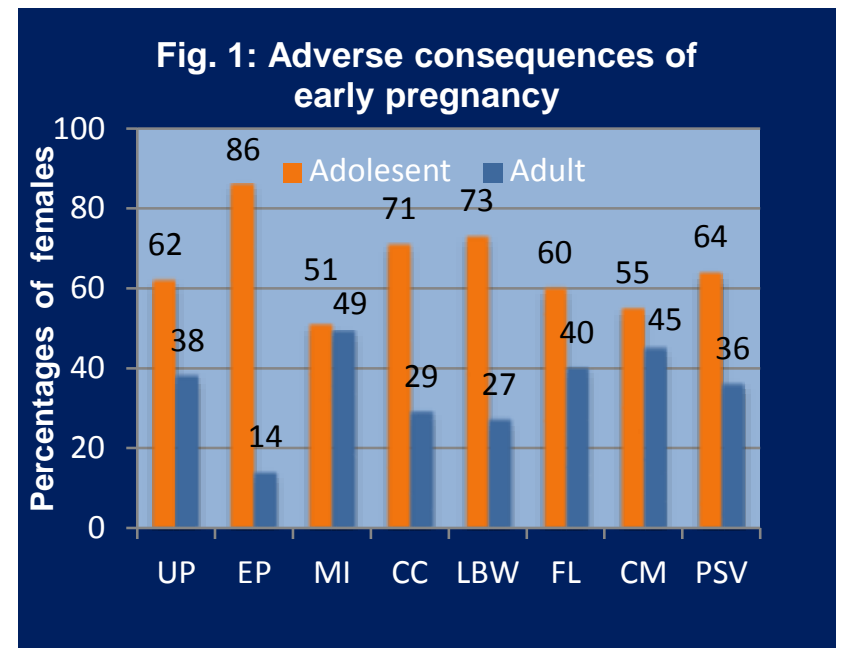

$U P=$ unintended pregnancy, $E P=$ eclampsia and preeclampsia, $M I=$ malaria infection, $C C=$ cervical cancer,$L B W=$ low birth weight $F L=$ fetal loss, $C M=$ child malnutrition, $P S V=$ physical $\&$ sexual violence

In addition to participating in organized educational activities and indoor games, club attendees each received a small picture book with family planning information in Bengali. This miniature book was designed to be attractive and practical to teenagers, with a bejeweled mirror as the cover and a keychain ring on one end (Figure 2).

\section{Shasthya Shebikas (SS)}

brac manages community health volunteers, Shasthya Shebikas, who visit clients door-to-door (about 200 households per month) to provide basic health, nutrition and newborn care, as well as FP education. They also sell basic health commodities and contraceptives. icddr,b built upon this model and trained 67 of these volunteers to counsel married adolescent girls on the persistent use of short-acting contraceptive methods and promote the uptake of long-acting reversible contraceptive methods (LARCs). The SS's were trained to clarify common misconceptions and fears, advise on possible side effects and provide referrals for LARC provision. In addition, they were trained to accompany the girls to the referral facility to receive LARCs, should the girl chose to do so.

\section{Marriage Registrars}

Marriage registrars, are appointed by the Government of Bangladesh under Ministry of Law, Justice and Parliamentary Affairs, to register marriages and divorces within a given area or locality. icddr,b trained 16 Marriage Registrars (13 Muslim Marriage registrars (Kazis), 1 Christian, and 2 Hindu Marriage Registrars) and 26 marriage counselors or assistants to the marriage registrars to counsel couples on FP from a religious viewpoint and to distribute the FP book to newlywed men. This 'gift' was meant to better engage the husbands and increase their involvement in FP related issues. 


\section{RESULTS}

Through their participation in the MAG clubs, engagement with Shasthya Shebikas, and information received from the Kazis, married adolescent girls in the intervention areas had an overall increased ability to receive and use FP information. This was significantly higher as compared to the control areas [5]. We found that knowledge and support for FP increased among girls, their husbands, and their communities in the intervention areas.

A greater proportion of girls (72.6\%) in the intervention areas at the end of the study were using modern family planning methods as compared to those in the control areas $(63.5 \%)$. Additionally, a higher proportion reported having conversations about FP with their husbands (97.5\% vs. $84.7 \%)$.

Unmet need for family planning (i.e. non-pregnant participants who wanted to delay their next birth by two or more years but were not using any contraceptive methods) was significantly lower among married adolescent girls in the intervention areas (16.2\%) than that of the control areas $(20.7 \%)$ [5].

\section{Married Adolescent Girls Club (MAG Club)}

Despite some difficulty in attending all club sessions (only $36 \%$ of girls attended 9 or more of the 12 club sessions) (Figure 3) due to household obligations, the MAG clubs were highly successful:

- All girls expressed enthusiasm for the benefits of the MAG clubs and appreciation of the opportunity to learn about FP methods and to clarify misconceptions, fears, and superstitions.

- Girls emphasized the value of the MAG clubs as a forum to exchange real-life experiences with their peers and to develop a peer network.

- The FP picture book and the provision of snacks for mothers and children at club meetings were both highly well-received. Nearly all girls requested that the MAG clubs be continued.
Fig. 3: Club attendance of married adolescent girls

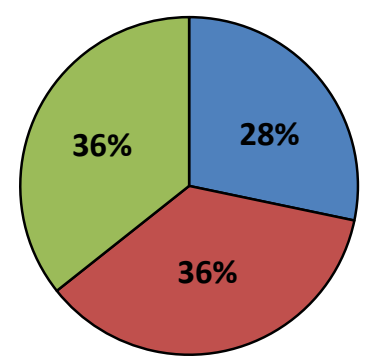

$\square 1$ to 4 sessions attended

5 to 8 sessions attended

$\square 9$ to 12

sessions

attended

\section{Shasthya Shebikas (SS)}

- A total of 64 girls received LARCs over the one year course of the Shasthya Shebikas visiting period, with girls' acceptance of LARCs increasing progressively throughout the year.

- Interviews with married adolescent girls revealed a strong acceptance of Shasthya Shebikas and an appreciation for their role in facilitating access to contraceptive methods.

- In some situations, the mothers, aunts, or in-laws prohibited girls obtaining LARCs due to fears and spiritual concerns.

\section{Marriage Registrars}

- A total of 52 newlywed couples received the FP picture book only from the Muslim Marriage Registrars (Kazis) over the one year intervention period.

- The Kazis had the opportunity to provide the informational FP picture book directly to the husbands of 44 newly married adolescent girls at the time of marriage registration. The remaining 8 couples collected the 'giff' later from their office.

- The newlywed couples who received the FP picture book from the Kazis expressed appreciation and positive feedback.

"It was a mistake to have a child at this stage. If I would use any contraceptive method and if I had the baby at a later stage, that would have been better. I did not know about any contraceptive methods before. No one suggested us to take a contraceptive method of told about the consequences of early pregnancy. If I knew it before, I would have taken a contraceptive method from the beginning. Now I am aware, this should not happen again." 


\section{KEY RECOMMENDATIONS}

- The Married Adolescent Girls' Club (MAG Club) was an effective and well-received strategy for empowering married girls and increasing their knowledge and use of FP. The government could leverage its existing resources and workforce in urban areas specifically in the slums by replicating the MAG Club model to improve married adolescent girls' knowledge and access to FP information and services which sequentially will help in reducing unmet need of FP and unintended pregnancy among this most vulnerable group.

- Involvement of marriage registrars was necessary to the success of the project interventions. The government can engage marriage registrars to provide necessary FP information to the newlywed husbands during marriage registration to enhance male involvement in FP programme.

- Giving enhanced training on long-acting contraceptive methods to Shasthya Shebikas increased married adolescent girls' knowledge and use of LARCs. In the urban areas, capacity building of the community health workers through GO-NGO collaboration could further improve FP service provision especially LARC uptake for birth spacing among married adolescent girls.

- Early marriage is a central component to the physical, social, and economic risks of early pregnancy, and girls from urban slums are especially vulnerable. Action should be taken to raise community awareness in enforcing the legal age minimum for marriage of 18 years for girls.

- Relevant stakeholders from Ministry of Local Government, Rural Development \& Co-operatives (LGRD\&C), policy makers, and Health and FP programme planners and managers should collaborate to identify geographic 'hotspots' - areas with concentrations of girls at risk of child marriage, early pregnancy, and unmet need of FP. Reproductive health issues of married adolescents' girls should be considered as a national priority and special effort should be given in designing program for them.

- Further research is required to explore the scopes and opportunities of replicating the 'Married Adolescent Girls' Club (MAG Club)' model in rural settings by utilizing government's existing infrastructure and resources to prevent adolescent motherhood.

\section{REFERENCES}

1. Child, early and forced marriage legislation in 37 AsiaPacific countries. Inter-Parliamentary Union (IPU) and World Health Organization (WHO), 2016. Pg: 24-27.

2. National Institute of Population Research and Training (NIPORT), Mitra and Associates, and ICF International. 2016. Bangladesh Demographic and Health Survey 2014. Dhaka, Bangladesh and Rockville, Maryland, USA: NIPORT, Mitra and Associates, and ICF International.

3. Huda, F.A., Chowdhuri, S., Ahmed, A., \& Sarker, B.K. (2014). Prevalence of unintended pregnancy and need for family planning among married adolescent girls living in urban slums of Dhaka, Bangladesh. Dhaka: Centre for Reproductive Health/icddr,b.
4. Santhya, K. (2011). Early marriage and sexual reproductive health vulnerabilities of young women: a synthesis of recent evidence from developing countries. Current Opinion in Obstetrics \& Gynecology. 23(5): 334-339.

5. Huda FA; Mahmood HR; Afrin S; Ahmmed F; Ahmed A; Haque NA; Alam A; and Sarker BK. (2017). "Expanding Access to Integrated Family Planning Intervention Packages for Married Adolescent Girls in Urban Slums of Dhaka, Bangladesh" STEP UP Research Report. Dhaka: icddr,b.

\footnotetext{
Suggested citation

Fauzia Akhter Huda, Nancy Termini LaChance. 2018. "Expanding Access to Family Planning for Married Adolescent Girls in the Urban Slums of Dhaka," STEP UP Policy Brief, February 2018. Dhaka: icddr,b.
} 